\title{
Prosthetic Rehabilitation of an Acquired Maxillary Defect in a Patient with a Compromised Dentition
}

\author{
1Dhanushka L Bandara, ${ }^{2}$ JA Vajira P Jayasinghe
}

\begin{abstract}
Background: The goal of prosthodontic rehabilitation entitles preservation of the remaining dentition and a long-term maintenance care, thus ensuring the stability of the dentition and the prosthesis. This becomes crucial in a patient with maxillary acquired defects where the social, behavioral, and the functional changes are involved. Status of the remaining dentition, the size, and extent of the lesion will mainly determine the overall prosthetic treatment plan.
\end{abstract}

Aim: This study aims to elaborate the importance of meticulous treatment planning in the prosthetic rehabilitation of a patient who presented with a maxillary acquired defect.

Case report: This clinical report describes the management of a patient with maxillary defect, where the remaining dentition has become further compromised due to inadequate maintenance care, thus resulting in a challenge in the prosthetic rehabilitation.

Conclusion: Rehabilitation of an acquired maxillary defect with a compromised dentition, using definitive closed hollow bulb obturator, took care of the different domains of care, giving an improved quality of life to the patient.

Clinical significance: Careful treatment planning with an aim to preserve the existing dentition and provide adequate maintenance care is essential for a successful outcome in the prosthetic management of patients with maxillary acquired defects.

Keywords: Case report, Maxillary acquired defect, Maxillary hollow bulb obturator, Prosthetic rehabilitation.

How to cite this article: Bandara DL, Jayasinghe JAVP. Prosthetic Rehabilitation of an Acquired Maxillary Defect in a Patient with a Compromised Dentition. Int J Experiment Dent Sci 2018;7(1):30-34.

\section{Source of support: Nil}

Conflict of interest: None

\section{BACKGROUND}

Prosthetic rehabilitation of an acquired maxillary defect poses a great challenge to the clinician, and this task is

\footnotetext{
${ }^{1,2}$ Senior Lecturer

${ }^{1}$ Division of Periodontology, Department of Oral Medicine and Periodontology, Faculty of Dental Sciences, University of Peradeniya, Peradeniya, Sri Lanka

${ }^{2}$ Department of Prosthetic Dentistry, Faculty of Dental Sciences University of Peradeniya, Peradeniya, Sri Lanka

Corresponding Author: Dhanushka L Bandara, Senior Lecturer, Division of Periodontology, Department of Oral Medicine and Periodontology, Faculty of Dental Sciences University of Peradeniya, Peradeniya, Sri Lanka, Phone: +94777279486, e-mail: dhanulb@yahoo.com
}

met by means of an obturator prosthesis. The main objective of prosthetic obturation is closure of the maxillary defect and separation of the oral cavity from sinonasal cavities. ${ }^{1}$ In addition, an obturator restores function and esthetics, preserves the associated structures, and contributes to the patient's perception of improved quality of life. ${ }^{2}$ However, this becomes more challenging when providing a definitive obturator prosthesis for a patient who had been on an obturator for a long time and presents with a compromised remaining dentition due to lack of adequate maintenance.

This case report describes the prosthetic rehabilitation of such a patient with an acquired palatal defect, using a closed bulb hollow obturator.

\section{CASE REPORT}

A 52-year-old male presented requesting to replace the metal hollow bulb obturator he had used for 15 years following a partial maxillectomy on the right side. Following examination and the necessary investigations, several problems were revealed that needed to be addressed during the treatment planning. Both his arches were partially dentate with Aramany class I defect ${ }^{3}$ with missing 16 on the opposite side of the defect (Fig. 1). Furthermore, class III Kennedy mandibular arch with a bounded saddle was the only region with opposing dentition suitable for chewing (Fig. 2). Extensive caries involved with 17 had resulted in nonvitality and tooth 15 showed poor prognosis due to failed endodontics with periapical periodontitis,

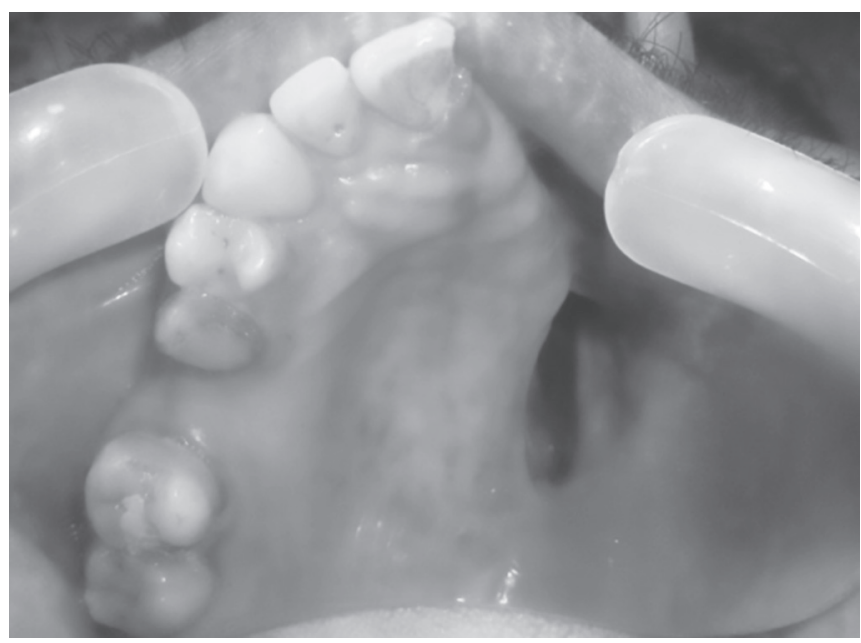

Fig. 1: Maxillary arch with the defect 


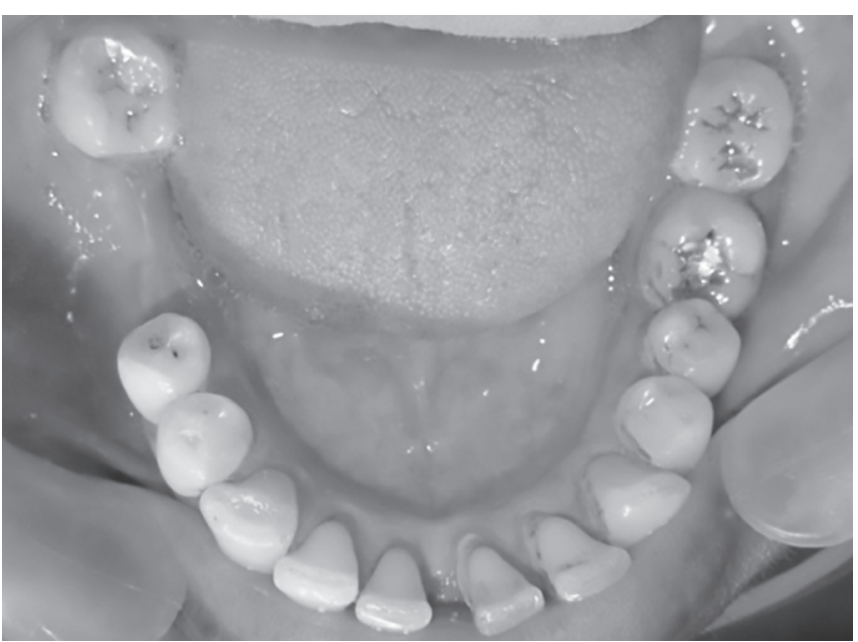

Fig. 2: Mandibular arch

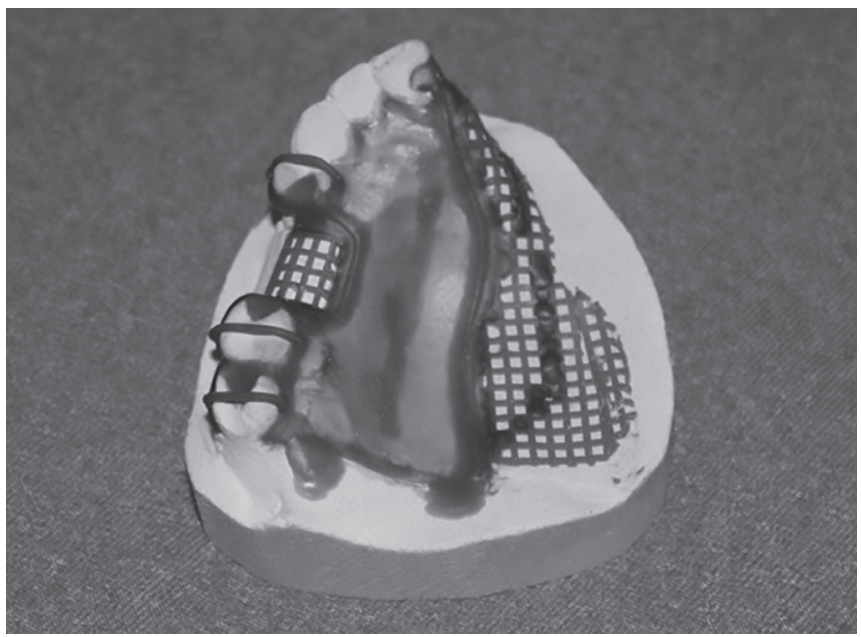

Fig. 4: Wax pattern for the maxillary denture framework

grade II mobility, and unsalvageable cuspal fracture. However, 15 was a strategic tooth holding support and retentive elements of the existing prosthesis, thus the extraction of 15 had to be followed by addition for the obturator and placing soft lining over the site to facilitate non-traumatic healing. Simultaneously, satisfactory plaque control was established and endodontic treatment of 17 was carried out. Due to its strategic position in the arch, establishing the long-term prognosis of 17 was crucial. Thus, considering the remaining tooth substance of 17 , a surveyed metal cast restoration with amalgam nayyar core was planned (Fig. 3).

Following taking the primary impressions with irreversible hydrocolloid alginate (Aroma Fine DF II, Fuji, Japan), the resultant casts were surveyed for designing of the cobalt-chromium mandibular removable partial denture (RPD) and the maxillary obturator prosthesis. A tripodal framework with following components was designed for the obturator according to Aramany's guidelines and Kennedy class I RPD design principles with a few modifications (Fig. 4 and Table 1).

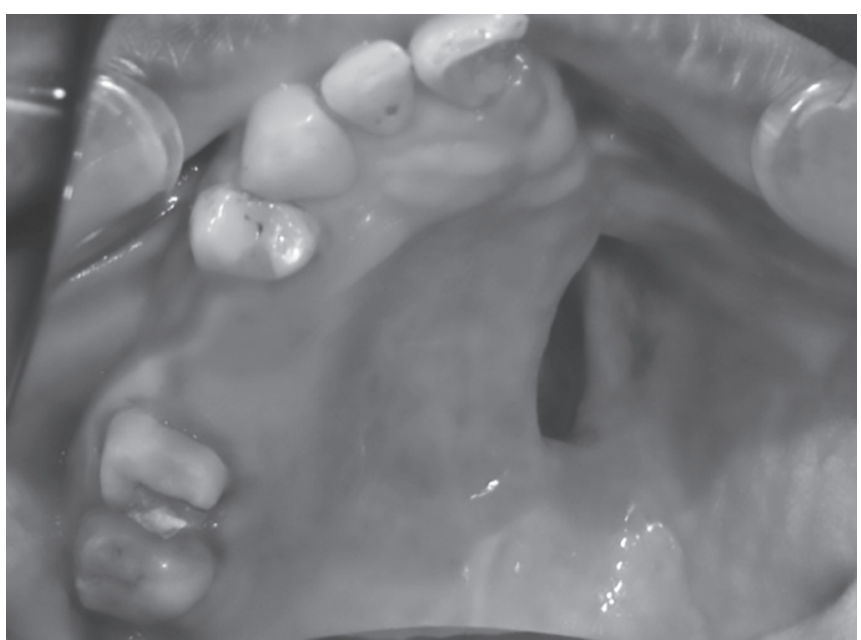

Fig. 3: Tooth preparation of 17 for the metal crown

Table 1: Components of the denture design

\begin{tabular}{|c|c|c|}
\hline Element & Components & Location \\
\hline \multirow[t]{2}{*}{ Support } & Occlusal rests & $14,17,18$ \\
\hline & Cingulum rest & 11 \\
\hline \multirow[t]{4}{*}{ Retention } & Circumferential clasps & $17,18-\mathrm{DB}$ undercut \\
\hline & & 14-MB undercut \\
\hline & $\begin{array}{l}\text { Wrought wire flexible } \\
\text { clasp arm }\end{array}$ & 11 \\
\hline & Guide plates & 14,18 \\
\hline $\begin{array}{l}\text { Denture base } \\
\text { connector }\end{array}$ & $\begin{array}{l}\text { Retentive mesh of the } \\
\text { denture }\end{array}$ & $\begin{array}{l}\text { Extended over the defect } \\
\text { area to maximize the } \\
\text { effect }\end{array}$ \\
\hline $\begin{array}{l}\text { Bracing } \\
\text { effect }\end{array}$ & $\begin{array}{l}\text { Palatal minor and } \\
\text { major connectors }\end{array}$ & $\begin{array}{l}\text { Maximum extension } \\
\text { to cover all the palatal } \\
\text { surfaces of maxillary teeth }\end{array}$ \\
\hline
\end{tabular}

The treatment plan was discussed with the patient and the consent was obtained. Following cementation of the metal crown on 17, the patient was ready for the next prosthetic session.

Subsequently, following tooth preparations, master impressions were taken with regular body silicone (Orma plus mono-phase, Major Dental, Italy) using autopolymerizing acrylic spaced custom trays.

On the following visit, the metal frameworks were tried-in and jaw relation recordings were carried out. The wax try-in was carried out in the next visit, and esthetics and occlusion in function were assessed. Upon patient's approval, they were sent to the laboratory for final processing in heat-cured acrylic.

To make the obturator part, the defect impression was made in heavy body silicone (Ormaplus, Major Dental, Italy), and the fine molding was done with a tissue conditioner (White Tissue Conditioner, Shofu, Japan), while the patient performed the necessary head, jaw, and swallowing movements. Subsequently, this addition was processed in acrylic allowing future adjustments and 


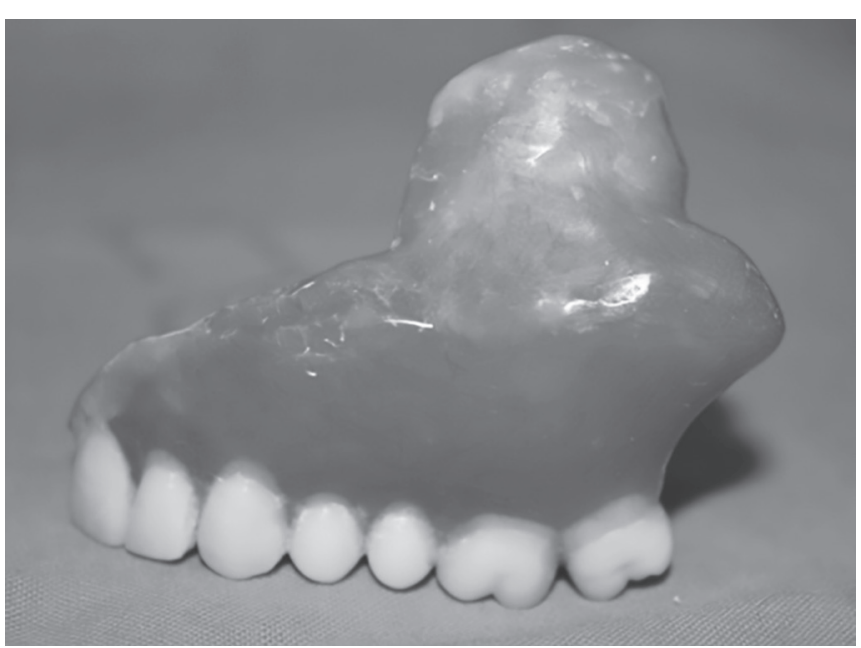

Fig. 5: View of the obturator part of the prosthesis

relining. Furthermore, it was made hollow to minimize the weight of the obturator (Fig. 5).

On the next visit both maxillary and mandibular prostheses were assessed for harmonized function and the prostheses were delivered (Figs 6 and 7). The patient was instructed on the insertion and removal of the prostheses and their maintenance and hygiene.

Patient was highly satisfied with the esthetic and functional outcomes. He was enrolled into a 3-month recall period to evaluate the overall prognosis including the status of the prosthesis, abutments, plaque control, and hygiene of the prosthesis.

\section{DISCUSSION}

A successful prosthetic design is the basis for the proper functioning of the prosthesis. Thus, the designing of this maxillary obturator was carefully carried out utilizing the remaining palate and dentition to maximize retention, support, and stability. ${ }^{4,5}$ Moreover, when the patient presented with a compromised dentition, ensuring a better long-term prognosis of the remaining dentition is mandatory.

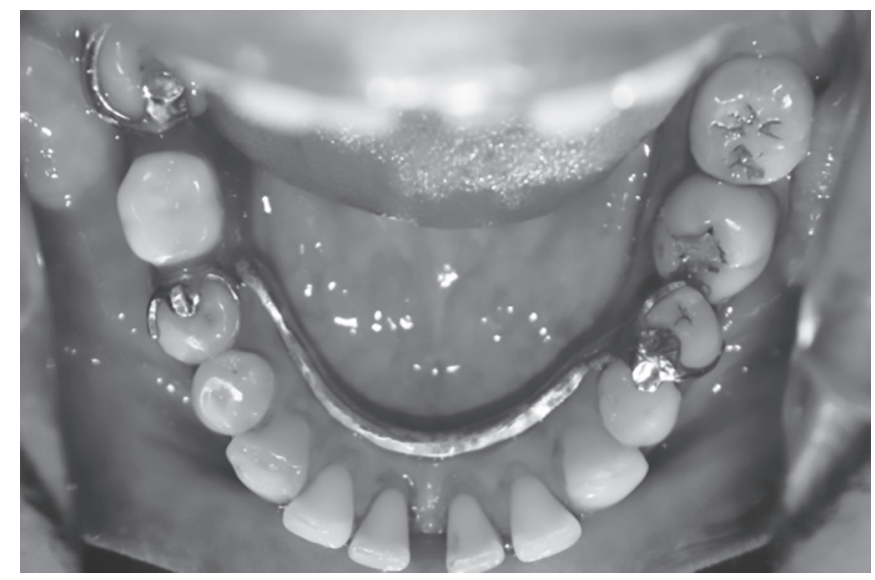

Fig. 6: Mandibular metal denture-occlusal view
The definitive obturator had two components, a metallic framework and an acrylic resin obturator bulb, and the defect in this case corresponded to Aramany's class I occurring in one-half of the palate. The metallic framework stabilizes anticipated cantilever forces along fulcrum line, whereas the remaining teeth and the palate provide stability for the prosthesis during mastication and speech.

In the framework, the main aim of the rigid palatal plate (major connector) and rests is to provide the tooth and mucosa support, distributing the load to the remaining natural teeth and to the other structures equally as much as possible. Furthermore, palatal connector provides greater tissue-bearing surface to resist upward forces and a greater tripodization to improve leverage.

Multiple occlusal rests are suggested to improve stability and support for the obturator prostheses and minimize the movement of the prosthesis toward the tissue. ${ }^{5}$ Occlusal rests should also be located as close to the defect as possible and adjacent to edentulous areas. ${ }^{6,7}$ Thus, a cingulum rest was placed on 11 , the closest abutment to the defect and a rest mesio-occlusally on 18 , the most distal abutment to the defect. Other occlusal rests were distributed on 14 and 17 , the abutment teeth adjacent to the edentulous area. Moreover, occlusal rests seats were prepared to direct occlusal forces along the long axis of the abutment teeth.

The structures in the remaining maxilla, amenable to provide retention, were limited to the remaining natural teeth and the borders of the defect. The number, position, and periodontal status of the remaining teeth are the most critical factors in deciding the placement of retentive units. Thus, as retentive units, a wrought wire clasp on 11 and cast circumferential clasps on buccal sides on 14,17 , and 18 were placed. The clasp design on 11 had to deal with several problems. Presence of large undercuts in relation to 11, which is in the esthetic zone, highly compromised the placement of a cast chromium clasp (CCC).

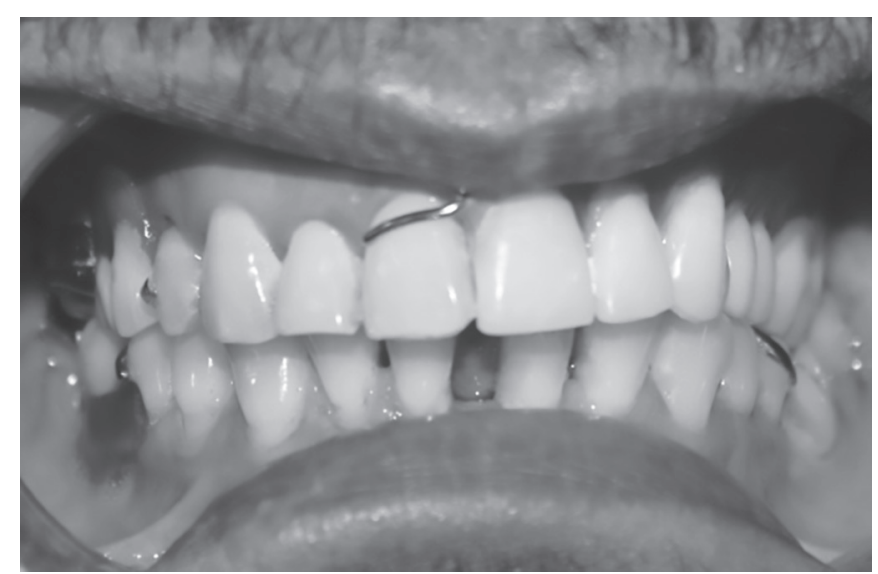

Fig. 7: Postoperative anterior view 
The CCC covers a large area of the tooth and, as a result, a large area of the metal is displayed. Thus, due to their relative rigidity, a well-defined limited-sized undercut should be employed. On the contrary, being a strategic clasp adjacent to the defect, it was essential to place a clasp over 11. This was overcome by placing a wrought wire clasp on 11. Wrought wire clasps are esthetically more acceptable than CCCs due to different light reflections from the round surface. Additionally, they flex in all directions and, as a result, they can engage larger undercuts and may, therefore, be less visible.,

Moreover, guide planes were used to ensure precise placement of the prosthesis, more predictable retention, and greater degree of stability. They also aid in the retention by resisting vertical displacement of the obturator and disengaging the retentive clasp arms. Palatal guide planes were also used for additional bracing and stability. Although increasing the height of the lateral wall could be used to enhance the retention, to minimize the weight, it was not considered.

The retention and stability of the obturator were further enhanced by reducing the weight of the prosthesis on the unsupported side, by making the obturator portion hollow. It improves the cantilever mechanics of suspension and avoids overtaxing of the remaining supporting structures. Further, it optimizes the patient comfort and aids in speech. Hollow bulb designs may have an open or closed top. In open obturators, nasal secretions can accumulate leading to odor and also add more weight. Further, difficulty in polishing and cleaning the internal surface, from saliva and mucous crusts, and the inability to obtain support from the superior aspect in the defect area pave the decision for a closed hollow bulb obturator.

Use of a flexible silicone material is another way to increase the retention of the obturator portion. It is also less irritant than hard acrylic resin. In addition, silicone obturators are lightweighted, and ease of insertion and removal are an additional advantage in this prostheses. ${ }^{10}$ However, due to the financial limitations, it was not considered in this patient.

To ensure good stability, the prosthesis was extended maximally in all lateral directions, and adequate bracing components were added. Moreover, to reduce the stress created by lateral forces, correct selection of an occlusal scheme, elimination of premature occlusal contacts, and wide distribution of stabilizing components are mandatory. ${ }^{11,12}$

This case report described a successful maxillary defect rehabilitation with a conventional obturator prosthesis that uses various clasps as retention components. Sometimes, however, a conventional obturator prosthesis is unable to provide adequate retention, stability, and support. In such cases, use of magnets, swing-lock retentive design systems, precision attachments, and placement of osseointegrated implants enhance the retention, thus the final outcome. ${ }^{12}$

The use of multiple precision attachments provides increased stability and retention of the prosthesis, as well as improved water and air tightness. Moreover, they improve esthetics in comparison with conventional clasping on incisors as terminal abutments adjacent to a large defect. ${ }^{13}$

In addition to attachments, osseointegrated implants can be used in both the defect and nondefect sides of the maxilla to provide better support and retention. ${ }^{12,13}$ On the defect side, alveolar bone, the zygomatic buttress, pterygoid plates, or horizontally between the cortices of the anterior hard palate are the potential sites for implant placement. In addition, implants are able to reduce movement of the prosthesis and encourage axial loading of the implant. Therefore, a combination of fixed implant supported and removable prosthesis can be considered as an alternative. ${ }^{14}$ However, in this case, osseointegrated implants were not preferred since the patient rejected to receive implant surgery due to financial, social, and psychological reasons.

Despite the treatment modality, changes in the tissues supporting a maxillofacial prosthesis may be more rapid than in those supporting a more conventional prosthesis. Therefore, the occlusion and base adaptation must be reevaluated frequently and corrected by selective grinding of the occlusion or refitting the base of the prosthesis. ${ }^{15,16}$ Moreover, long-term wearing of a prosthesis elevates the risk of caries and periodontal disease ${ }^{17}$ as well as the risk of soft tissue trauma. Thus, a well-planned maintenance phase is essential to minimize the complications and maintain the achieved successful outcome.

Therefore, considering the patient's motivation, plaque control ability, and the degree of maintenance care needed for the prosthesis, this patient was enrolled in a monthly recall program.

\section{CONCLUSION}

The patient presented in this case had been using an obturator prosthesis for 15 years and at the time of presentation, the condition of the remaining dentition had further deteriorated.

The concept of rehabilitation of patients with maxillary defects provides a means of enhancing mastication, deglutition, speech, and esthetics, thus, finally providing a functional solution to the compromised state of the patient. Rehabilitation of an acquired maxillary defect in a patient, using definitive closed hollow bulb obturator, took care 
of the different domains of care, giving the patient an opportunity to live a life as close to normal as possible.

\section{CLINICAL SIGNIFICANCE}

The patient presented in this case had been using obturator prosthesis for 15 years and at the time of presentation, the condition of the remaining dentition had further deteriorated. Therefore, this case highlights the importance of a properly planned long-term maintenance program for such patients to minimize the future complications and to preserve what is remaining.

\section{ACKNOWLEDGMENTS}

Authors greatly acknowledge the support received from the patients and the assisting staff of the Department of Prosthetic Dentistry, Faculty of Dental Sciences, University of Peradeniya, Sri Lanka.

\section{REFERENCES}

1. Devlin H, Barker GR. Prosthetic rehabilitation of the edentulous patient requiring a partial maxillectomy. J Prosthet Dent 1992 Feb;67(2):223-227.

2. Kornblith AB, Zlotolow IM, Gooen J, Huryn JM, Lerner T, Strong EW, Shah JP, Spiro RH, Holland JC. Quality of life of maxillectomy patients using an obturator prosthesis. Head Neck 1996 Jul-Aug;18(4):323-334.

3. Aramany MA. Basic principles of obturator design for partially edentulous patients. Part I: Classification. J Prosthet Dent 1978;40:554-557.

4. Desjardins RP. Obturator prosthesis design for acquired maxillary defects. J Prosthet Dent 1978 Apr;39(4):424-435.
5. Gay WD, King GE. Applying basic prosthodontic principles in the dentulous maxillectomy patient. J Prosthet Dent 1980 Apr;43(4):433-435.

6. Keyf F. Obturator prostheses for hemimaxillectomy patients. J Oral Rehabil 2001 Sep;28(9):821-829.

7. Parr GR, Tharp GE, Rahn AO. Prosthodontic principles in the framework design of maxillary obturator prostheses. J Prosthet Dent 1989 Aug;62(2):205-208.

8. Curtis TA. Treatment planning for intraoral maxillofacial prosthetics for cancer patients. J Prosthet Dent 1967 Jul;18(1):70-72.

9. Khan SB. Aesthetic clasp design for removable partial dentures: a literature review. SADJ 2005 Jun;60(5):190-194.

10. Rieger J. Speech outcomes in patients rehabilitated with maxillary obturator prosthesis after maxillectomy: a prospective study. Int J Prosthodont 2002 Mar-Apr;15(2):139-144.

11. Aramany MA. Basic principles of obturator design for partially edentulous patients. Part II: Design principles. J Prosthet Dent 1978;40:656-662.

12. Roumanas ED, Chang TL, Beumer J. Use of osseointegrated implants in the restoration of head and neck defects. J Calif Dent Assoc 2006 Sep;34(9):711-718.

13. Salinas TJ, Guerra LR, Rogers WA. Aesthetic considerations for maxillary obturators retained by implants. Pract Periodontics Aesthet Dent 1997 Apr;9(3):265-276.

14. Walter JD. Obturators for acquired palatal defects. Dent Update 2005 Jun;32(5):277-285.

15. Schwartzman B, Caputo A, Beumer J. Occlusal force transfer by removable partial denture designs for a radical maxillectomy. J Prosthet Dent 1985 Sep;54(3):397-403.

16. Matsuyama M, Tsukiyama Y, Tomioka M, Koyano K. Subjective assessment of chewing function of obturator prosthesis wearer. Int J Prosthodont 2007 Jan-Feb;20(1):46-50.

17. Coulthwaite L, Verran J. Potential pathogenic aspects of denture plaque. Br J Biomed Sci 2007;64(4):180-189. 